International Journal of Psychological Research and Reviews
(ISSN:2639-6041)

\title{
Suspicious Jealousy Is Related to Anxious Attachment and Is Mediated By Fear of Intimacy
}

Gabriel Dominguez-Pereira, PhD ${ }^{1}$, Tiffany Field, $\mathrm{PhD}^{1,2}$, James Vivian, PhD ${ }^{1}$, Sybil L. Hart, $\mathrm{PhD}^{3}$ and Debra Bendell, $\mathrm{PhD}^{1}$

${ }^{1}$ Fielding Graduate University; ${ }^{2}$ University of Miami School of Medicine; ${ }^{3}$ Texas Tech University

\begin{abstract}
Relationships between insecure attachment (anxious and avoidant), fear of intimacy and romantic jealousy (suspicious and reactive) were explored in this study. The Experiences in Close Relationships Questionnaire, the Fear-of-Intimacy Scale, and the Multidimensional Jealousy Scale were administered to a sample of 210 ethnically diverse adults via Qualtrics Panels. Anxious attachment, fear of intimacy, and suspicious jealousy were positively correlated. Conversely, negative associations were noted between avoidant attachment and reactive jealousy, and between fear of intimacy and reactive jealousy. Mediation analysis revealed that fear of intimacy mediated the effect of anxious attachment on suspicious jealousy and marginally mediated the effect of avoidant attachment on suspicious jealousy. These results are consistent with the transactional model of jealousy and they uniquely specify that fear of intimacy is a significant mediator of the relationship between anxious attachment and suspicious jealousy.
\end{abstract}

Keywords: reactive jealousy, suspicious jealousy, anxious attachment, avoidant attachment, fear of intimacy, romantic jealousy.
${ }^{*}$ Correspondence to Author: Gabriel Dominguez-Pereira, $\mathrm{PhD}$

Fielding Graduate University

How to cite this article:

Gabriel Dominguez-Pereira, Tiffany Field, James Vivian, Sybil L. Hart, and Debra Bendell.Suspicious Jealousy Is Related to Anxious Attachment and Is Mediated By Fear of Intimacy. International Journal of Psychological Research and Reviews, 2019, 2:23

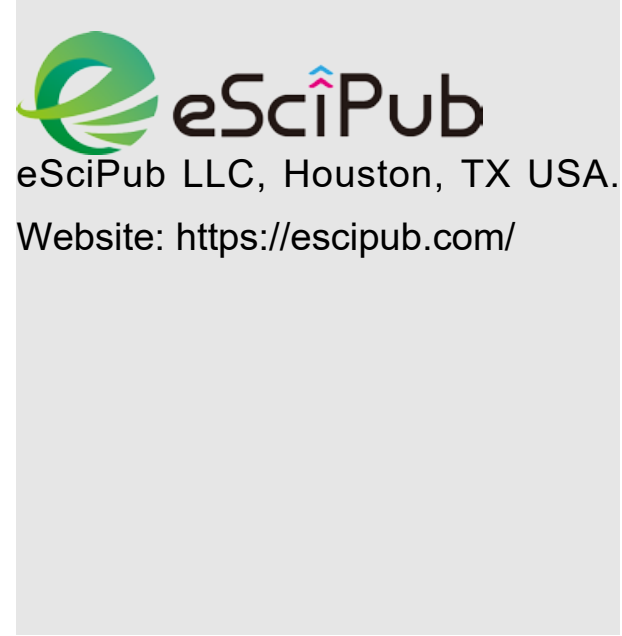


In the present study, relationships were explored between insecure attachment (i.e. anxious and avoidant), fear of intimacy, and romantic jealousy (i.e., reactive and suspicious). This study represents an extension of research on romantic jealousy that has shown a distinction between suspicious (not based in reality) and reactive (based in reality) types of romantic jealousy. The theoretical framework upon which this study rests is the transactional model of jealousy (Bringle, 1991; Rydell \& Bringle, 2007). This model is rooted in a functionalistic theory of perception that posits that human perceptions are learned reactions on the basis of the transactions with the environment. Consequently, the transactional model of jealousy conceives romantic jealousy as a social construct that is embedded within a social context. Romantic jealousy is regarded as resulting from a transaction between the person and the social environment in which both the stimulus and the person contribute to the experience of jealousy.

The transactional model of jealousy defines romantic jealousy as an "aversive emotional reaction that occurs as a result of a partner's extra dyadic relationship that is real, imagined, or considered likely to occur" (Bringle \& Buunk, 1985 , p. 242). The transactional model of jealousy offers a multidimensional approach that identifies two types of jealousy: reactive and suspicious jealousy. The suspicious jealousy involves primarily thoughts, behaviors, and feelings that are usually experienced in the absence of any major jealousy-evoking event.

In the Transactional Model of Jealousy, jealousy has been conceptualized as a multifactorial phenomenon in which different types of romantic jealousy have distinctive antecedents and manifestations (Bringle, 1991; Rydell \& Bringle, 2007). In this model, reactive jealously is associated with positive individual characteristics and/or aspects of the relationship, and suspicious jealousy is associated with negative individual characteristics and/or aspects of the relationship. In the current study, insecure attachment styles (anxious and avoidant) were expected to positively correlate with fear of intimacy, and fear of intimacy, in turn, was expected to positively correlate with suspicious jealousy, but negatively correlate with reactive jealousy. Fear of intimacy was expected to mediate the relationships between insecure attachment style (anxious and avoidant) and suspicious jealousy. Assessing this model on the two different types of jealousy would be expected to lead to more effective interventions.

\section{Fear of Intimacy and Reactive Jealousy}

From the perspective of the transactional model of jealousy (Bringle, 1991; Rydell \& Bringle, 2007), reactive jealousy occurs when concrete transgressions violate critical aspects of the relationship, such as the expectation of sexual exclusivity. Thus, reactive jealousy is expected to be a direct response to the identification of concrete events that might threaten the relationship. Reactive jealousy has been positively correlated with love (Pfeiffer \& Wong, 1989), with closeness (Attridge, 2013) and with intimacy (Guerrero,1998; Knobloch, 2001). If reactive jealousy has been positively correlated with love, closeness, and intimacy, a negative association between fear of intimacy and reactive jealousy would be expected.

\section{Fear of Intimacy and Suspicious Jealousy}

Firestone and Catlett (2006) theorized that "people's fear of intimacy predisposes behaviors that ward off closeness in their relationships, which in turn heightens their jealous reactions" (p. 241). These authors argued that jealous reactions are a combination of self-attacks and aggressive attitudes experienced more frequently by individuals who deny or avoid competing directly for a love object. The theoretical account by Firestone and Catlett (2006) supports the notion that there is a positive association between fear of intimacy and romantic jealousy. However, the way these authors conceptualized jealousy is consistent with suspicious jealousy, not reactive jealousy, 
as delineated by the transactional model of jealousy (Bringle, 1991; Rydell \& Bringle, 2007).

Theoretical and empirical evidence suggest that while reactive jealousy has the purpose of protecting the relationship from threats caused by rivals, suspicious jealousy seems to be a more complex phenomenon with different and more complex underlying mechanisms. Another way in which fear of intimacy may play a role in the causal chain that results in suspicious jealousy is through creating a distorted image of the romantic partner that can be used as a "reasonable" reason to avoid intimacy. This notion would be consistent with Knobloch et al.'s (2001) findings that a comfort with closeness was negatively associated with suspicious jealousy and Attridge's (2013) findings that suspicious jealousy was negatively correlated with closeness. That suspicious jealousy may be used as a defense mechanism to lessen fear of intimacy and prevent closeness would be consistent with the dependency risk regulation model delineated by Murray, Holmes, and Collins (2006), which postulates that distancing in romantic relationships is used as a selfprotective strategy by insecure individuals who withdraw their emotional investment from close relationships to avoid being hurt.

\section{Attachment Style, Romantic Jealousy, and Fear of Intimacy}

Since the attachment system is activated to manage thoughts, feelings, and behaviors triggered by relational threats, the mental model underlying attachment styles should be expected to influence the experience, as well as the expression of jealousy (Guerrero, 1998). In this theoretical perspective on attachment and jealousy, jealousy could be conceptualized as a response to a situation that threatens separation or a change in the relationship and where the experience and responses are determined by individual attachment styles (Guerrero, 1998). People with insecure attachment styles may be more prone to interpreting situations as threatening to their relationships and experience more jealousy than people with secure attachment styles (Guerrero, 1998). Empirical research has shown that secure attachment was associated with less jealousy (Radecky-Bush, Farell, \& Bush, 1993).

Given that attachment styles are associated with different relationship expectations, it has been proposed that each style has a somewhat different reaction to possible relationship threats and consequently "because romantic relationships are likely to be attachment relationships, individual differences in jealousy are likely to parallel individual differences in attachment behavior" (Sharpsteen \& Kirkpatrick, 1997, p. 628). This has been supported by empirical evidence showing that women with anxious attachment styles, for example, tend to express higher levels of jealousy (Collins \& Read, 1994). And, empirical evidence suggests that people with anxious attachment styles express more jealousy than people with secure attachment styles (Fraley \& Shaver, 2016). Further, a recent study showed how anxiously attached individuals reported more jealousy in response to jealousy-eliciting laboratory situations (Kim et al., 2017).

Some research has documented associations between different attachment styles and different types of jealousy. These studies have shown that individuals with anxious and avoidant attachment-styles displayed greater suspicious jealousy (Guerrero, 1998; Rydell \& Bringle, 2007). The study by Rydell and Bringle (2007) further found a negative association between avoidant attachment style and reactive jealousy and a positive association between anxious attachment style and reactive jealousy. The positive association between anxious attachment and reactive jealousy was further confirmed by studies conducted by Knobloch, Solomon, and Cruz (2001). The positive association between avoidant attachment and suspicious jealousy was further suggested by the results obtained in a more recent study in which individuals with avoidant attachment styles experienced considerably more jealousy when compared to individuals with secure 
attachment styles (Guclu et al, 2017). In this study, only individuals with secure attachment styles experienced reactive jealousy (Güclü et al., 2017).

Individuals with insecure attachment styles have scored higher on fear of intimacy scales
(Knobloch et al, 2001; Sharpsteen \& Kirkpatrick, 1997). Avoidant attachment in particular has been associated with fear of intimacy (Guclu et al, 2017; Guerrero, 1998). Individuals with avoidant attachment have also reported lower levels of commitment in their relationships (Mikulincer \& Erev, 1991).

Table 1 Frequency Distributions for Education, Household Income, Marital Status, Gender, Religious Affiliation, Sexual Identity, and Ethnicity ( $N=210)$

\begin{tabular}{|c|c|c|c|}
\hline \multicolumn{2}{|l|}{ Descriptor } & Frequency & Percentage \\
\hline \multicolumn{4}{|l|}{ Education } \\
\hline & High school degree & 56 & 26.7 \\
\hline & Some college but no degree & 62 & 29.5 \\
\hline & Associate's degree & 24 & 11.4 \\
\hline & Bachelor's degree & 51 & 24.3 \\
\hline & Other & 17 & 8.1 \\
\hline \multicolumn{4}{|c|}{ Household Income } \\
\hline & Less than $\$ 50,000$ & 126 & 60.0 \\
\hline & $\$ 50,000$ to $\$ 99,999$ & 58 & 27.6 \\
\hline & $\$ 100,000$ or more & 26 & 12.4 \\
\hline \multicolumn{4}{|c|}{ Marital Status } \\
\hline & Single, Never Married & 81 & 38.6 \\
\hline & Married & 87 & 41.4 \\
\hline & Other & 42 & 20.0 \\
\hline \multicolumn{4}{|l|}{ Gender } \\
\hline & Male & 50 & 23.8 \\
\hline & Female & 159 & 75.7 \\
\hline & Other & 1 & 0.5 \\
\hline \multicolumn{4}{|c|}{ Religious Affiliation } \\
\hline & Protestant Christian & 61 & 29.0 \\
\hline & Roman Catholic & 41 & 19.5 \\
\hline & Other & 108 & 51.4 \\
\hline \multicolumn{4}{|c|}{ Sexual Identity } \\
\hline & Heterosexual & 179 & 85.2 \\
\hline & Homosexual & 16 & 7.6 \\
\hline & Other & 15 & 7.1 \\
\hline \multicolumn{4}{|l|}{ Ethnicity } \\
\hline & Asian & 15 & 7.1 \\
\hline & Black or African American & 30 & 14.3 \\
\hline & Caucasian & 143 & 68.1 \\
\hline & Latino & 12 & 5.7 \\
\hline & Other & 10 & 4.8 \\
\hline
\end{tabular}

\section{Mediation Hypothesis}

The previous theoretical discussion and empirical evidence led to the mediation hypothesis for this study. Baron and Kenny (1986) assert that mediation requires (a) that the predictors (anxious/avoidant attachment) are directly associated with the proposed mediator (fear of intimacy); (b) the mediator (fear of intimacy) is directly associated with the outcome (suspicious jealousy), and (c) the effects of the predictors (anxious/avoidant attachment) either disappear or diminish in magnitude once the 
mediator is taken into account. Therefore, these were the hypotheses for the current study. Because the mediator (fear of intimacy) was hypothesized, and found, to be negatively associated with reactive jealousy, fear of intimacy was not thought to be part of the causal chain explaining reactive jealousy. For this reason, a mediation analysis was not conducted for reactive jealousy.

\section{Methods}

\section{Participants}

A sample of 210 ethnically diverse adults (from 19 to 74 years of age) was recruited via Qualtrics panels. All the participants resided in the United States. To be eligible to participate in the study, participants had to confirm that they were 18 years old or older, and that they were currently involved or had been involved in a romantic relationship.

Table 1 illustrates the frequency distributions corresponding to education, household income, marital status, gender, religious affiliation, sexual identity, and ethnicity. The frequency distribution corresponding to marital status shows that never married people and married people are represented in this sample. The distribution corresponding to gender shows that the sample is predominantly women. The average age is $36.8(S D=11.64)$.

\section{Procedures}

A linear multiple regression method (fixed model, $\mathrm{R}^{2}$ deviation from zero) supported a power analysis conducted to determine the sample size needed to obtain moderate size effects $\left(f^{2}=.15\right)$ with adequate power $(.80)$. The sample of the study was obtained through Qualtrics panels, which records response data that can be downloaded into SPSS for analysis. In addition to screening out respondents who did not fully meet the criteria for this study, Qualtrics enabled Speeding Check which was another measure for screening out respondents who completed the survey in less than one third of the average survey completion time. In order to improve the quality of the data provided by the respondents, a question was included that was intended to obtain the respondent's thoughtful commitment to provide the best answer to each question in the survey. Low quality responses were omitted from the data base.

\section{Measures}

Multidimensional Jealousy Scale (MJS). To assess jealousy, the Multidimensional Jealousy Scale (MJS) was included. The MJS is the first validated measure of multidimensional jealousy (Pfeiffer \& Wong, 1989). It is a 24-item questionnaire that assesses three types of jealousy, including cognitive (suspicious) jealousy, emotional (reactive) jealousy, and behavioral (suspicious) jealousy. Good reliability and validity have been reported. Cronbach's alphas for the emotional, cognitive, and behavioral subscales were $0.85,0.92$, and 0.89 respectively (Pfeiffer \& Wong, 1989). The Cronbach's alphas for the current study were .90 for suspicious jealousy and .94 for reactive jealousy.

While the emotional subscale ranges from 1 (very pleased) to 7 (very upset), the behavioral subscale ranges from 1 (never) to 7 (all the time), and the cognitive subscale ranges from 1 (all the time) to 7 (never). The suspicious jealousy subscales (cognitive and behavioral) assess how often suspiciousness occurred concerning a partner or rival, for example: "I suspect that $X$ is secretly seeing someone of the opposite sex." For theoretical and empirical reasons and because an earlier study showed a significant correlation between the cognitive and behavioral subscales (Rydell \& Bringle, 2001), these two subscales were combined for a measure of suspicious jealousy. Emotional (reactive) jealousy was assessed by asking subjects how upset they would feel in response to hypothetical jealousy-evoking situations, for example: " $X$ is flirting with someone of the opposite sex."

The Fear of Intimacy Scale (FIS). To measure fear of intimacy, the Fear-of-Intimacy Scale (FIS; Descutner \& Thelen, 1991) was included. Itemanalysis yielded a 35 -item scale with high 
internal consistency (.93) and high test-retest reliability (.89). Other studies have confirmed the validity and reliability of the FIS (Bumby \& Hansen, 1997; Doi \& Thelen, 1993). Cronbach's alpha for this study was .92 .

Factor analyses have revealed one primary factor, which provides support for the construct validity of the scale as unidimensional in nature. The scale is particularly useful and unique in that it can be used to assess fear of intimacy regardless of whether the individual is currently involved in an intimate relationship (Descutner \& Thelen, 1991; Doi \& Thelen, 1993). The FIS presents each item on a 5-point scale ranging from "not at all a characteristic of me" (1) "to extremely characteristic of me" (5) through items such as: "I would feel uneasy with $X$ depending on me for emotional support."
Experiences in Close Relationships Questionnaire (ECR). To measure attachment style, the ECR was included. This scale was developed by Brennan, Clark, and Shaver (1998) to assess two dimensions: anxious and avoidant attachment style. Other studies have confirmed the validity and reliability of the ECR (Lopez \& Gormley, 2002). This scale is comprised of two 18-item subscales for each dimension, for a total of 36 items. The items on the ECR are rated on a 7-point scale, where 1 is Strongly Disagree and 7 is Strongly Agree. The attachment-related anxiety scale uses items such as the following: "I worry a lot about my relationships," The attachment-related avoidance scale includes items such as "I prefer not to show a partner how I feel deep down." The Cronbach's alphas for this study were .90 for avoidant and .95 for anxious attachment.

Table 2 Descriptive Statistics for Jealousy, Fear of Intimacy, and Attachment

\begin{tabular}{|c|c|c|c|c|c|c|}
\hline Variable & & $N$ & Minimum & Maximum & Mean & Standard Deviation \\
\hline Suspicious Jealousy & 210 & & 16 & 106 & 50.2 & 20.94 \\
\hline Reactive Jealousy & 210 & & 8 & 56 & 40.2 & 12.35 \\
\hline Fear of Intimacy & 209 & & 39 & 155 & 89.0 & 23.56 \\
\hline Avoidant Attachment & 209 & & 18 & 123 & 58.8 & 20.55 \\
\hline Anxious Attachment & 209 & & 18 & 122 & 69.2 & 26.49 \\
\hline
\end{tabular}

\section{Results}

\section{Descriptive Statistics}

Table 2 illustrates the descriptive statistics for the variables jealousy, fear of intimacy, and attachment. The fear of intimacy mean score of 89.0 is higher than the normative mean score of 78.7 reported by Descutner and Thelen (1991), $t$ $=5.677, p<.001$. The anxious attachment mean score of 69.2 is higher than the normative mean score of 62.2 reported by Brennan, Clark, and Shaver (1998), $t=3.810, p<.001$. The avoidant attachment mean score of 58.8 is higher than the normative mean score of 52.7 reported by Brennan, Clark, and Shaver (1998), $t=3.524, p$ $=.001$. The reactive jealousy mean score of
40.2 is lower than the normative mean score of 42.4 reported by Rydell and Bringle (2007), $t=$ $2.488, p=.014$. The suspicious jealousy mean score of 50.2 is higher than the normative mean score of 41.9 reported by Rydell and Bringle (2007), $t=5.839, p<.001$.

\section{Correlation Analysis}

A correlation analysis was conducted to evaluate the relationships between suspicious jealousy, reactive jealousy, fear of intimacy, avoidant attachment, and anxious attachment. As can be seen in Table 3, based on one-tail Pearson correlations, all of these variables were significantly correlated with each other at least at the $p<.01$ level. 
Table 3 Intercorrelations for Suspicious Jealousy, Reactive Jealousy, Fear of Intimacy, Avoidant Attachment, and Anxious Attachment

\begin{tabular}{lllllll}
\hline & Measure & 1 & 2 & 3 & 4 & 5 \\
\hline 1 & Suspicious Jealousy & - & & & & \\
2 & Reactive Jealousy & -.10 & - & & \\
3 & Fear of Intimacy & $.33^{* * *}$ & $-.24^{* * *}$ & - & \\
4 & Avoidant Attachment & $.33^{* * *}$ & $-.25^{* * *}$ & $.80^{* * *}$ & - & \\
5 & Anxious Attachment & $.37^{* * *}$ & $.20^{* *}$ & $.34^{* * *}$ & $.22^{* *}$ & - \\
\hline
\end{tabular}

Note. $n=203$. Correlations are one-tail. ${ }^{* *} p<.01,{ }^{* \star *} p<.001$

\section{Mediation Analysis}

To test the mediating effects of fear of intimacy on the relationship between attachment styles and suspicious jealousy, a regression-based approach was used. Via PROCESS software relevant coefficients and indirect effects were generated (Hayes, 2013).

The total effect model for anxious attachment on suspicious jealousy was significant, $R^{2}=.14, p$
$<.001$. The direct effect of anxious attachment on suspicious jealousy was significant, effect = $.229, p<.001$. A normal theory test indicated the indirect effect was significant, effect $=.061, p=$ .005. The data support that fear of intimacy mediates the effect of anxious attachment on suspicious jealousy. See Figure 1.

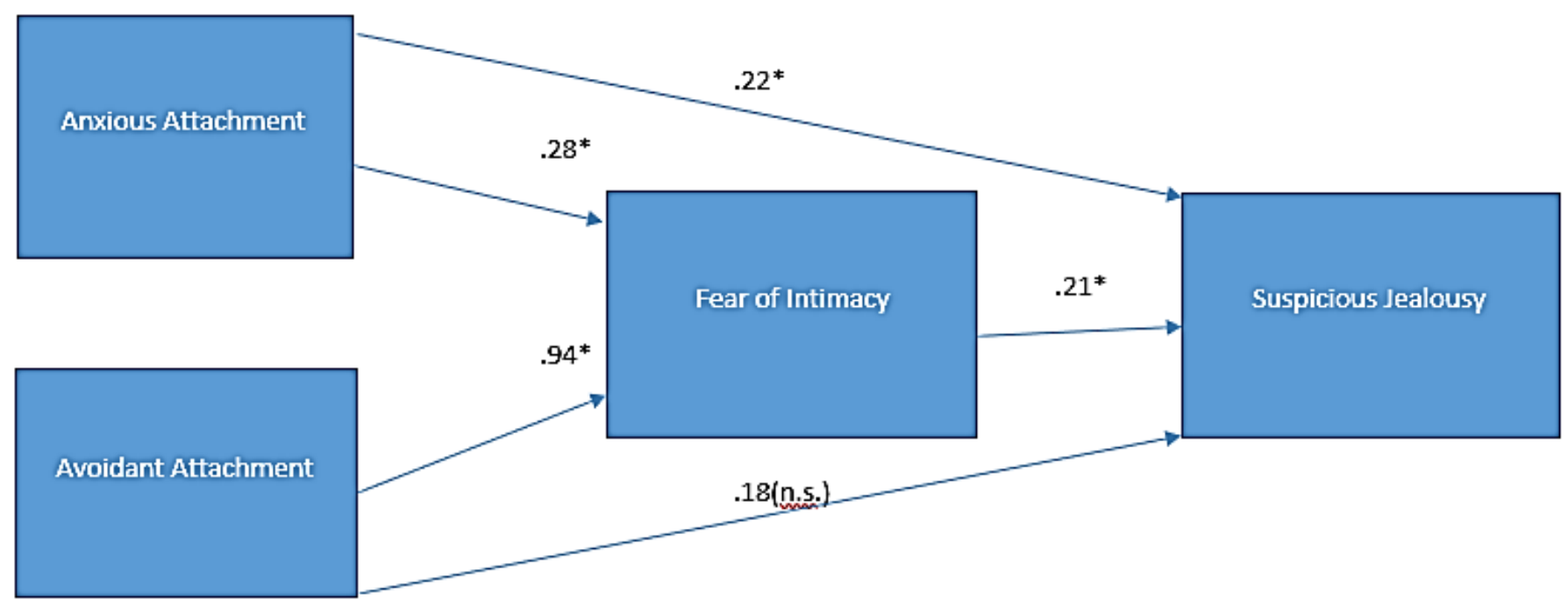

Indirect effect (anxious attachment on SJ)

$[b=.061, p=.005]$

Indirect effect (avoidant attachment on SJ)

$[b=.172, p=.07]$

Figure 1: Fear of intimacy mediates the effects of insecure attachment on suspicious jealousy. NOTE: Unstandardized regression coefficients were inserted into the path diagram above

The total effect model for avoidant attachment $p<.001$. The direct effect of avoidant on suspicious jealousy was significant, $R^{2}=.11$, attachment on suspicious jealousy was not 
significant, effect $=.186, p=.13$. A normal theory test indicated the indirect effect was marginally significant, effect $=.172, p=.07$. The data marginally support that fear of intimacy mediates the effect of avoidant attachment on suspicious jealousy. See Figure 1.

\section{Summary of Results}

Taken pairwise, there is a significant positive correlation between insecure attachment (anxious and avoidant), fear of intimacy, and suspicious jealousy. Conversely, significant negative correlations were found between avoidant attachment and reactive jealousy and between fear of intimacy and reactive jealousy.

The results of the study further demonstrate that fear of intimacy mediates the effect of anxious attachment on suspicious jealousy; however, the indirect effect of fear of intimacy on the relationship between avoidant attachment and suspicious jealousy was marginal. The pattern of results is consistent with what Baron and Kenny (1986) called partial mediation insofar as the association between anxious attachment and suspicious jealousy was diminished in magnitude once the mediator (fear of intimacy) was taken into account.

\section{Discussion}

The results of this study offer empirical evidence in favor of a multidimensional approach to romantic jealousy consistent with the transactional model of jealousy (Bringle, 1991; Rydell \& Bringle, 2007) and support studies of romantic jealousy that have shown a distinction between the suspicious and reactive types of romantic jealousy (i.e., Attridge, 2013; Rydell \& Bringle, 2007). In the present study, suspicious jealousy was positively associated with anxious attachment, avoidant attachment, and fear of intimacy. Conversely, reactive jealousy was negatively associated with fear of intimacy and avoidant attachment. Anxious attachment was positively associated with both types of jealousy. In general, these findings clearly distinguished reactive jealousy and suspicious jealousy as being related to different attachment styles.

\section{Reactive Jealousy and Anxious Attachment}

Although the finding that anxious attachment style was positively associated with reactive jealousy is consistent with previous studies (Knobloch et al., 2001; Rydell \& Bringle, 2007), this continues to be an intriguing association. A possible explanation for the positive association of anxious attachment with both reactive and suspicious jealousy is the ambivalent nature of individuals with an anxious attachment style (Brennan et al, 1998; Joel, MacDonald, \& Shimotomai, 2011). Those individuals tend to suffer a persistent worry of abandonment and to draw their partners in and then push them away (Guerrero, 1998; Hazan \& Shaver, 1987).

The ambivalence that characterizes individuals with anxious attachment may be the reason why these individuals have been found to express both reactive and suspicious jealousy in this study and in previous studies (Knobloch et al., 2001; Rydell \& Bringle, 2007). There is a possibility that because anxiously attached individuals view their romantic relationships as a positive source in their lives, they express reactive jealousy as a way of protecting their relationships. However, because they also fear abandonment, they may occasionally express suspicious jealousy as a way of creating distance and minimizing the fear of abandonment. This may be the reason why anxiously attached individuals have been found to not experience as much intimacy as they desire (Mikulincer \& Erev, 1991). It might also be that those with greater attachment anxiety are more suspicious because they tend to be hypervigilant of cues of rejection and because of their biased processing of social information.

\section{Fear of Intimacy and Suspicious Jealousy}

The present study was a first attempt to include fear of intimacy as a mediational variable in the relationship between adult attachment and romantic jealousy. This study demonstrated that fear of intimacy mediates the relationship between anxious attachment style and suspicious jealousy and marginally mediates the relationship between avoidant attachment and 
suspicious jealousy. The theoretical account by Firestone and Catlett (2006) and the findings of this study support the notion that suspicious jealousy is self-generated, and not necessarily triggered by a rival. Suspicious jealousy is thought to involve primarily thoughts, behaviors, and feelings that are usually experienced in the absence of any major jealousy-evoking event (Bringle, 1991; Rydell \& Bringle, 2007).

That fear of intimacy mediates the relationship between anxious attachment style and suspicious jealousy is also in line with Guerrero's (1998) finding that individuals with anxious attachment style react to threats by distancing themselves instead of attempting to minimize the threat by the rival. This notion is consistent with findings by Knobloch et al. (2001) that a comfort with closeness was negatively associated with suspicious jealousy and findings by Attridge (2013) that suspicious jealousy was negatively correlated with closeness. That suspicious jealousy may be used as a defense mechanism to prevent closeness and reduce fear of intimacy is consistent with the dependency risk regulation model delineated by Murray, Holmes, and Collins (2006). This model postulates that distancing in romantic relationships is used as a self-protective strategy by insecure individuals who withdraw emotional investment from close relationships to avoid being hurt.

From the perspective of the dependency risk regulation model (Murray et al., 2006), it may be argued that people with fear of intimacy prioritize self-protection at the expense of commitment, which is accomplished through self-produced suspicious jealousy. Subsequently, suspicious jealousy interferes with closeness and intimacy, which, in turn, may contribute to more jealousy (Firestone \& Catlett, 2006).

The notion that suspicious jealousy is selfgenerated is consistent with a transactional model of jealousy (Bringle, 1991; Rydell \& Bringle, 2007), which posits that suspicious jealousy is characterized by cognitive elaboration that is frequently constructed around ambiguous clues that oftentimes result in a search for evidence intended to confirm the unsubstantiated cognitive ideation. It is also consistent with empirical research that has shown that people experiencing suspicious jealousy minimize or ignore objective information that might be used to disconfirm the cognitive elaboration leading to suspicious jealousy (Tarrier, Beckett, Harwood, \& Bishay, 1990).

\section{Avoidant Attachment and Fear of Intimacy}

The correlation analysis supported the predicted positive relationship between avoidant attachment and fear of intimacy. However, the extremely high correlation between fear of intimacy and avoidant attachment may have resulted from overlapping content in the two measures. The overlapping content, in turn, might explain why the indirect effect of fear of intimacy on the relationship between avoidant attachment and suspicious jealousy was only marginal.

\section{Limitations}

Some studies have examined and demonstrated how infidelity influences the experience of romantic jealousy (e.g., Burchell \& Ward, 2011; Harris, 2009; Murphy, Vallacher, Shackelford, Bjorklund, \& Yunger, 2006). A limitation of this study was not assessing the impact of infidelity and how this factor could have impacted the manifestation of the different types of jealousy.

Another limitation of the present study was that a relationship-level analysis of jealousy was not measured. A relationship-level analysis would have allowed a comparison of self-perception of jealousy with the perception of jealousy by partners. This limitation neglects the consideration of findings by White (1981) that there are differences in the way jealousy is expressed and perceived within each couple.

Another important methodological limitation was the way in which romantic jealousy was measured. The research on romantic jealousy relied on either hypothetical scenarios in which participants try to imagine themselves in 
situations and then attempt to predict how they might feel or react, or in retrospective recall of jealous experiences. This is considered a methodological limitation because reactions to hypothetical scenarios can be inaccurate representations of how people feel and react in real emotional situations. A large body of literature on emotional forecasting suggests that people are often inaccurate in predicting emotional feelings in a variety of situations (e.g., Totterdell, Parkinson, Briner, \& Reynolds, 1997; Wilson \& Gilbert, 2005).

The predominance of females and heterosexual individuals in the sample, and that the jealousy measure was tailored for heterosexual individuals, should further be considered limitations of this study. Additionally, futures studies should take into consideration the differences that might result from subjects currently involved in a relationship and those who are reporting on a past relationship, what kind of relationship were they in (e.g., casually dating, committed, engaged, married) and how long were they, or have they been in those relationships.

\section{Final Considerations}

The outcomes of this study confirm the transactional model of jealousy (Bringle, 1991; Rydell \& Bringle, 2007) supporting a more thorough understanding of the different antecedents and mediating factors associated with romantic jealousy. They emphasize the importance of conceiving romantic jealousy as a multifactorial phenomenon in which different types of jealousy possess distinctive antecedents.

The findings of this study further indicate that future studies should continue to explore the effects of fear of intimacy on suspicious jealousy. Clearly, one factor such as fear of intimacy is not enough to explain suspicious jealousy. Instead, the results of this research confirm White's (1981) emphasis of the notion that jealousy should not be conceived as a simple emotion but as a complex set of interrelated cognitive, emotional, and behavioral factors. The positive association between fear of intimacy and suspicious jealousy is expected to have implications for future studies on romantic jealousy.

\section{References}

1. Attridge, M. (2013). Jealousy and relationship closeness: Exploring the good (reactive) and bad(suspicious) sides of romantic jealousy. SAGE Open, pp., 1-16.

2. Barelds, D. P. H., \& Dijkstra, P. (2006). Reactive, anxious and possessive forms of jealousy and their relation to relationship quality among heterosexuals and homosexuals. Journal of Homosexuality, 51, 183-198.

3. Baron, R. M., \& Kenny, D. A. (1986). The moderator-mediator variable distinction in social psychological research: Conceptual, strategic, and statistical considerations. Journal of Personality and Social Psychology, 51, 11731182.

4. Brennan, K. A., Clark, C. L., \& Shaver, P. R. (1998). Self-report measurement of adult romantic attachment: An integrative overview. In J. A. Simpson \& W. S. Rhodes (Eds.), Attachment theory and close relationships (pp. 46-76). New York, NY: Guilford.

5. Bringle, R. G. (1991). Psychosocial aspects of jealousy: A transactional model. In P. Salovey (Ed.), The psychology of jealousy and envy (pp. 103-131). New York, NY: Guilford.

6. Bumby, K. M., \& Hansen, D. J. (1997). Intimacy deficits, fear of intimacy and loneliness among sexual offenders. Criminal Justice and Behavior, 24, 315-331.

7. Burchell, J. L., \& Ward, J. (2011). Sex drive, attachment style, relationship status and previous infidelity as predictors of sex differences in romantic jealousy. Personality and Individual Differences, 51(5), 657-661.

8. Collins, N. L., \& Read, S. J. (1994). Cognitive representations of attachment: The structure and function of working models. In K. Bartholomew \& D. Perlman (Eds), Advances in personal relationships: Vol. 5. Attachment processes in adulthood (pp.53-90). Bristol, PA: Kingsley.

9. Descutner, C. J., \& Thelen, M. H. (1991). Development and validation of a Fear-of-Intimacy Scale. Psychological Assessment, 3, 218-225.

10. Doi, S. C., \& Thelen, M. H. (1993). The Fear-ofIntimacy Scale: Replication and extension. Psychological Assessment, 5, 377-383.

11. Elphinston, R., Feeney, J., \& Noller, P. (2011). Measuring romantic jealousy: Validation of the Multidimensional Jealousy Scale in Australian 
Gabriel Dominguez-Pereira et al., IJPRR, 2019 2:23

samples. Australian Journal of Psychology, 63, 243-251.

12. Firestone, R. W., \& Catlett, J. (2006). Fear of intimacy. (10 ${ }^{\text {th }}$ ed.). Washington, DC: American Psychological Association.

13. Fraley, C. R., \& Shaver, P. R. (2016). Attachment, loss, and grief: Bowlby's views, new developments, and current controversies. In J. Cassidy \& P. R. Shaver (Eds.), Handbook of attachment: Theory, research, and clinical applications (3rd ed., pp. 40-62). New York, NY: Guilford Press.

14. Güclü, O., Senormanci, Ö., Senormanci, G., \& Köktürk, F. (2017). Gender differences in romantic jealousy and attachment styles. Psychiatry and Clinical Psychopharmacology, 27, 359-365.

15. Guerrero, L. K. (1998). Attachment-style differences in the experience and expression of romantic jealousy. Personal Relationships, 5, 273-291.

16. Harris, C. R. (2009). Jealousy. In H. T. Reis \& S. Sprecher (Eds.), Encyclopedia of human relationships (pp. 937-941). Thousand Oaks, CA: SAGE.

17. Hayes, A. F. (2013). Introduction to mediation, moderation, and conditional process analysis: $A$ regression-based approach. New York, NY: The Guilford Press. doi:10.1111/jedm.12050

18. Hazan, C., \& Shaver, P. (1987). Conceptualizing romantic love as an attachment process. Journal of Personality and Social Psychology, 29, 270280.

19. Joel, S., MacDonald, G., \& Shimotomai, A. (2011). Conflicting pressures on romantic relationship commitment for anxiously attached individuals. Journal of Personality, 79, 51-74.

20. Kim, K., Feeney, B., \& Jakubiak, B. (2017). Touch reduces romantic jealousy in the anxiously attached. Journal of Social and Personal Relationships. Advance online publication. doi:10.1177/0265407517702012

21. Knobloch, L. K., Solomon, D. H., \& Cruz, M. G. (2001). The role of relationship development and attachment in the experience of romantic jealousy. Personal Relationships, 8, 205-224.

22. Lopez, F. G., \& Gormley, B. (2002). Stability and change in adult attachment style over the firstyear college transition: Relations to selfconfidence, coping, and distress patterns. Journal of Counseling Psychology, 49, 366-364.

23. Mikulincer, M., \& Erev, I. (1991). Attachment style and the structure of romantic love. British Journal of Social Psychology, 30, 273-291.

24. Murphy, S. M., Vallacher, R. R., Shackelford, T. K., Bjorklund, D. F., \& Yunger, J. L. (2006). Relationship experience as a predictor of romantic jealousy. Personality and Individual Differences, 40(4), 761-769.

25. Murray, S. L., Holmes, J. G., \& Collins, N. L. (2006). Optimizing assurance: The risk regulation system in relationships. Psychological Bulletin, 132, 641-666.

26. Murray, S. L., Holmes, J. G., \& Griffin, D. W. (2000). Self-esteem and the quest for felt security: How perceived regard regulates attachment processes. Journal of Personality and Social Psychology, 78, 478-498.

27. Pfeiffer, S. M., \& Wong, P. T. P. (1989). Multidimensional jealousy. Journal of Social and Personal Relationships, 6, 181-196.

28. Radecky-Bush, C., Farell, A. D., \& Bush, J. P. (1993). Predicting jealous responses: The influence of adult attachment and depression on threat appraisal. Journal of Social and Personal Relationships, 10, 569-588.

29. Rydell, R. J., \& Bringle, R. G. (2007). Differentiating reactive and suspicious jealousy. Social Behavior and Personality, 35, 1099-1114.

30. Sharpsteen, D. J \& Kirkpatrick, L. A. (1997). Romantic Jealousy and Adult Romantic Attachment. Journal of personality and social psychology, 72, 627-640.

31. Stieger, S., Preyss, A. V., \& Voracek, M. (2012). Romantic jealousy and implicit and explicit selfesteem. Personality and Individual Differences, 52, 51-55.

32. Tarrier, N., Beckett, R., Harwood, S., \& Bishay, N. (1990). Morbid jealousy: A review and cognitivebehavioral formulation. British Journal of psychiatry, 157, 319-326.

33. Totterdell, P., Parkinson, B., Briner, R. B., \& Reynolds, S. (1997). Forecasting feelings: The accuracy and effects of self-predictions of mood. Journal of Social Behavior \& Personality, 12(3), 631-650.

34. White, G. L. (1981). A model of romantic jealousy. Motivation and Emotion, 5, 295-310.

35. Wilson, T. D., \& Gilbert, D. T. (2005). Affective forecasting: Knowing what to want. Current Directions in Psychological Science, 14, 131-134. 